\title{
Diamine oxidase-modified screen-printed electrode for the redox-mediated determination of histamine
}

\author{
Ricarda Torre, Estefanía Costa-Rama* ${ }^{*}$, Henri P. A. Nouws and Cristina Delerue-Matos
}

\begin{abstract}
Histamine is an important biogenic amine because of its role in immune responses and the regulation of physiological functions. It is also used as a food freshness indicator, so its maximum concentration in fish is legally regulated. Although several robust and sensitive methods for histamine detection are already available, it continues to be a challenge to develop simple and portable devices that allow rapid histamine screening at any point of the fish production chain. Thus, in this work, a simple, miniaturized and low-cost sensor for histamine analysis was developed. The construction of the sensor only takes $30 \mathrm{~min}$ and consists of the immobilization of the enzyme diamine oxidase on the surface of a screenprinted carbon electrode by cross-linking. The quantification of histamine was achieved by chronoamperometry $(+0.2 \mathrm{~V}$, $120 \mathrm{~s})$ using hexacyanoferrate (III) as a redox mediator. This selective sensor provided a low limit of detection $\left(0.97 \mathrm{mg} \mathrm{L}^{-1}\right)$ and accurate and precise results and was successfully applied to the analysis of spiked tuna and mackerel extracts, obtaining recovery values of $99-100 \%$. Moreover, the sensor shows good stability, maintaining $87.7 \%$ of its initial signal after 35 days.
\end{abstract}

Keywords: Amperometric biosensor, Enzymatic sensor, Biogenic amine, Histamine, Diamine oxidase, Redox mediator, Ferrocyanide, Screen-printed electrode

\section{Introduction}

Histamine is a low molecular weight biogenic amine produced by microbial decarboxylation of the amino acid histidine. It can be found in various kinds of foods such as meat, fish, and fermented foods (Biji et al. 2016; Papageorgiou et al. 2018). Although the low levels of histamine normally present in food are not considered a health risk, the intake of high amounts of histamine causes scombroid poisoning. This is also known as histamine fish poisoning since it is mostly related to the consumption of spoiled fish. This food poisoning continues to be a common cause of food intoxication worldwide and produces both physiological and toxicological effects (e.g., abdominal pain, diarrhea, vomiting, headache, urticaria...), the severity of which depends on the dosage (Feng et al. 2016; Hungerford 2010). The rapid increase of histamine levels in fish is mainly caused by the

\footnotetext{
* Correspondence: estefaniarama@graq.isep.ipp.pt

REQUIMTE/LAQV, Instituto Superior de Engenharia do Porto, Instituto

Politécnico do Porto, Rua Dr. António Bernardino de Almeida 431, 4200-072 Porto, Portugal
}

presence of large amounts of histidine and inappropriate storage conditions after capture (temperatures $>4{ }^{\circ} \mathrm{C}$ and/or long storage times) that promote bacterial activity (Kung et al. 2015; Silva et al. 1998; Tsai et al. 2005). Thus, in histidine-rich fish species, e.g., sardine, tuna, and mackerel, it is more likely that histamine is developed than in histidine-poor species such as hake. Moreover, histamine is not affected by freezing, heating, sterilization, or canning processes (Naila et al. 2010; Visciano et al. 2014). Hence, histamine is a reliable fish freshness indicator and its concentration is legally regulated: EU legislation establishes $200 \mathrm{mg} \mathrm{kg}^{-1}$ (for individual samples) and $100 \mathrm{mg} \mathrm{kg}^{-1}$ (as average) as limits for histidine-rich fish species (Off. J. Eur. Union. Comm. Regul. No 2073/2005 15 November 2005).

Therefore, histamine analysis is key not only to assure food freshness and quality, but also to avoid food intoxications. Analytical methods typically used for histamine analysis include separation techniques, e.g., chromatography (gas and liquid) or capillary electrophoresis, coupled to UV-Vis, fluorescence, or mass spectrometric 
detection (Almeida et al. 2012; Daniel et al. 2015; Evangelista et al. 2016; Nadeem et al. 2019; Nei et al. 2017; Papageorgiou et al. 2018). These methods are very robust and selective; however, they have drawbacks since they often require (1) long analysis times, (2) expensive and complex instrumentation (which need expensive maintenance and highly qualified operators), (3) tedious and time-consuming sample treatments (e.g., digestion and derivatization), and (5) large amounts of reagents and solvents, producing large amounts of waste. Moreover, the equipment is not portable; hence, on-site analysis is not possible.

Considering that the concentration of histamine undergoes a rapid increase when the storage conditions of the fish are not adequate (Kung et al. 2015; Silva et al. 1998; Tsai et al. 2005), the development of portable devices that allow the monitoring of its levels from fishing to the final consumer is of high interest. Electrochemical biosensors are interesting tools since they offer fast analysis and accurate results and show an excellent ability for miniaturization, providing portable platforms that allow decentralized analysis. Due to the increasing demand for fast and reliable information, the development of portable sensors is a continuously growing area. Furthermore, with the advances in smartphone technology and digital communication networks, sensors integrated with electronics are becoming essential tools in daily life (Dincer et al. 2019; Quesada-González and Merkoçi 2017; Zarei 2017).

In this context, several works reported electrochemical devices for histamine analysis (Ordóñez et al. 2016; Papageorgiou et al. 2018). Some of them were based on the electrochemical oxidation of histamine on modified electrodes such as carbon paste electrodes modified with carbon nanotubes (Stojanović et al. 2016) or rhenium oxides (Veseli et al. 2016), nafion-coated copper phosphate nanostructured screen-printed carbon electrodes (Lee et al. 2018), and glassy carbon electrodes modified with polystyrene-graphene oxide (Saghatforoush et al. 2014) or a carbon nanotube-coated polymer (Geto et al. 2014). These sensors usually require the pre-treatment of the electrodes and the use of metals, polymers, and/or nanomaterials, which increases the cost and construction time. Sensors based on electrodes modified with enzymes (Apetrei and Apetrei 2016; Gumpu et al. 2014; Pérez et al. 2013; Zeng et al. 2000), molecularly imprinted polymers (Akhoundian et al. 2017; Basozabal et al. 2014) and antibodies (Dong et al. 2017) are usually more selective due to the incorporation of a recognition element. However, the immobilization of these elements is often a complex and time-consuming task (Akhoundian et al. 2017; Apetrei and Apetrei 2016; Basozabal et al. 2014; Dong et al. 2017; Gumpu et al. 2014; Pérez et al. 2013; Zeng et al. 2000).
The biosensor developed in this work stands out for its simplicity without sacrificing analytical performance. Screen-printed electrodes were used to obtain a miniaturized, portable and robust sensor that allows analysis of a small sample volume $(30-40 \mu \mathrm{L})$. This sensor is a step forward regarding our previously developed histamine sensor (Torre et al. 2019) in which the enzyme diamine oxidase (DOX) was immobilized by cross-linking using glutaraldehyde and bovine serum albumin. In this work only glutaraldehyde was used, simplifying the sensor's construction and achieving better stability. On the other hand, the use of a redox mediator allowed histamine analysis through its electrochemical oxidation, improving the sensitivity (more than 100-fold) and selectivity of the sensor's response, and avoiding matrix effects of the fish samples. Thus, a very simple sensor was obtained that not only showed good analytical features (in terms of limit of detection, sensitivity, reproducibility, and stability), but was also cheap, small-sized, and able to perform on-site analysis using low amounts of reagents and samples.

\section{Methods/experimental}

\section{Solutions and equipment}

Diamine oxidase (DOX, $0.11 \mathrm{U} \mathrm{mg}^{-1}$ ), potassium hexacyanoferrate (III), biogenic amines (histamine, putrescine, spermine, tyramine, tryptamine, and phenylethylamine), and glutaraldehyde (GA) were supplied by Sigma-Aldrich. The fresh tuna and mackerel were purchased in a local market.

Working solutions of DOX, GA, histamine, and the other biogenic amines were prepared in $0.1 \mathrm{M}$ phosphate buffer (PB) pH 7.2. This $\mathrm{pH}$ was chosen because the supplier indicated that this is the optimum $\mathrm{pH}$ to dissolve the enzyme and because the ideal $\mathrm{pH}$ range is 6.3-7.4 when histamine is used as the enzymatic substrate.

Type I deionized water (resistivity $=18.2 \mathrm{M} \Omega \mathrm{cm}$ ) was used throughout the work. All the chemicals were of analytical reagent grade and were used without further treatment or purification.

A Metrohm-Autolab potentiostat/galvanostat (PGSTAT 101) controlled by NOVA software (v1.10) was used for the electrochemical measurements. Screen-printed electrodes (printed on a ceramic substrate $-3.4 \mathrm{~cm} \times 1.0 \mathrm{~cm}$ ), consisting of a circular-shaped carbon-ink working electrode (WE, $d=4 \mathrm{~mm}$ ), a silver-ink pseudoreference electrode (RE), and a carbon-ink counter electrode (CE) were used. These screen-printed carbon electrodes (SPCEs) and the suitable connector were purchased from DropSens.

\section{Enzyme immobilization}

The optimized procedure for the immobilization of the enzyme consisted of depositing $2 \mu \mathrm{L}$ of a $0.50-\mathrm{mg} \mu \mathrm{L}^{-1}$ DOX solution and $1 \mu \mathrm{L}$ of a $0.50 \% \mathrm{GA}$ solution on the 
WE of the SPCE, which was left to dry for $30 \mathrm{~min}$ at room temperature. The biosensor was ready to use after a washing step with buffer solution (0.1 M PB pH 7.2).

\section{Electrochemical analysis}

For the measurements, $20 \mu \mathrm{L}$ of a standard/sample solution and $20 \mu \mathrm{L}$ of a potassium hexacyanoferrate (III) solution ( $5 \mathrm{mM}$ in the optimized procedure) were deposited on the SPCE. After $5 \mathrm{~min}$, to allow the enzymatic reaction to occur, chronoamperograms were recorded at $+0.2 \mathrm{~V}$ for $120 \mathrm{~s}$, assuring that the current plateau was reached. The signal for each histamine concentration was the average of the currents obtained for the last $5 \mathrm{~s}$ of the chronoamperogram.

\section{Fish samples preparation}

Histamine was extracted from the fish samples (tuna and mackerel) following the same procedure as for the commercial R-Biopharm enzymatic test (R-Biopharm AG, n.d). This protocol was as follows: $20 \mathrm{~mL}$ of deionized water was added to $5.0 \mathrm{~g}$ of fish and mixed with a vortex mixer. This mixture was placed in a boiling water bath for $20 \mathrm{~min}$ and then centrifuged for $2 \mathrm{~min}$ at 10 , $000 \mathrm{~g}$. Finally, the supernatant was removed and stored at $-80^{\circ} \mathrm{C}$.

\section{Results and discussion}

In the presence of oxygen, DOX catalyzes the oxidation of histamine to the corresponding aldehyde (imidazole acetaldehyde), hydrogen peroxide, and ammonia (Fig. 1). In this work, the mediator hexanocyanoferrate (III) $\left(\left[\mathrm{Fe}(\mathrm{CN})_{6}\right]^{3-}\right)$ (i.e., the oxidized form of the mediator) was used to record the electrochemical signal. An increase of the current was observed at $+0.2 \mathrm{~V}$ when the concentration of histamine increased. This current increase was due to the oxidation of the mediator (that showed an anodic peak at $+0.12 \mathrm{~V}$ when a DOX/GA-modified electrode SPCE was used; Additional file 1: Figure S1). To be able to measure the electrochemical oxidation of the mediator, it must be previously reduced. This reduction could occur through the oxidation of $\mathrm{H}_{2} \mathrm{O}_{2}$ (produced during the enzymatic oxidation of histamine; Fig. 1) (Leonardo and Campàs 2016), which is common for other enzymatic sensors (Chaubey and Malhotra 2002; Gorton 1995). However, Keow et al. (Keow et al. 2012; Keow et al. 2007) showed that imidazole acetaldehyde produced during the enzymatic oxidation of histamine (Fig. 1) is oxidized at + $0.35 \mathrm{~V}$ (using a carbon-paste screen-printed electrode $v s$. an $\mathrm{Ag} / \mathrm{AgCl}$ referenceelectrode). Since $\mathrm{H}_{2} \mathrm{O}_{2}$ is oxidized at potentials higher than $+0.6 \mathrm{~V}$ (Chaubey and Malhotra 2002; Gorton 1995) and imidazole acetaldehyde is oxidized at $+0.35 \mathrm{~V}$, the predominant mechanism should be the one in which the mediator is reduced by the oxidation of imidazole acetaldehyde (indicated in Fig. 1). Therefore, histamine was detected indirectly through the electrochemical oxidation of the enzymatically generated hexacyanoferrate (II) $\left(\left[\mathrm{Fe}(\mathrm{CN})_{6}\right]^{4-}\right)$. The current intensity was measured by chronoamperometry, which is a simple detection technique that is very suitable for portable devices.

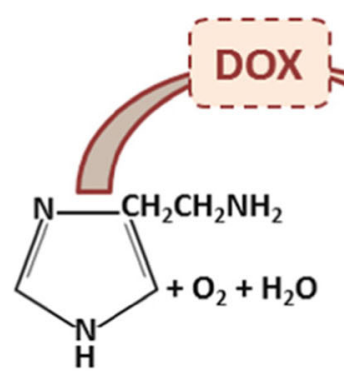

Histamine

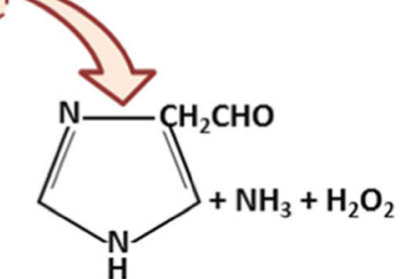

vs. $t$
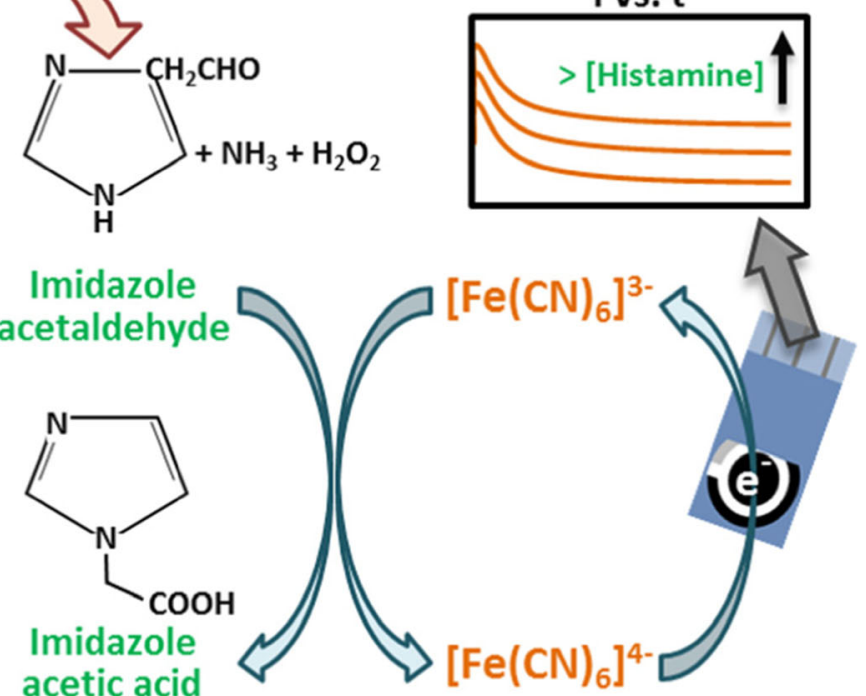

Fig. 1 Schematic representation of the proposed mechanism for the enzymatic and electrochemical reactions involved in the detection of histamine 


\section{Optimization studies}

To determine the most suitable chronoamperometric measuring potential, a cyclic voltammogram $(\mathrm{CV})$ of a 5.0-mM hexacyanoferrate (II) solution (in $0.1 \mathrm{MPB} \mathrm{pH}$ 7.2) using the sensor (DOX/GA/SPCE) was recorded. As can be seen in Additional file 1: Figure S1, an anodic peak at $+0.12 \mathrm{~V}$ and a cathodic peak at $-0.03 \mathrm{~V}$ were obtained. To guarantee the oxidation of the mediator, potentials starting at $+0.2 \mathrm{~V}$ were considered to record the chronoamperograms. A study to determine the best measuring potential was performed by recording chronoamperograms using histamine solutions of 25 and 75 $\mathrm{mg} \mathrm{L}^{-1}$ at $+0.20 \mathrm{~V}$ and $+0.25 \mathrm{~V}$. Similar analytical signals ( $\Delta i$, difference between $i$ for histamine and $i$ for blank) were obtained for both potentials (Fig. 2). Thus, $+0.20 \mathrm{~V}$ was chosen as the detection potential since this potential lowers the possibility of interference of other electroactive species that can be oxidized at higher potentials.

The immobilization of the enzyme on the working electrode is also crucial for the adequate performance of the sensor. A saturated enzyme solution $\left(0.50 \mathrm{mg} \mu \mathrm{L}^{-1}\right)$ was used. The effect of the GA concentration on the analytical signal was tested (Fig. 2). A GA concentration of $0.50 \%$ showed the highest $\Delta i$ for both 25 and $75 \mathrm{mg}$ $\mathrm{L}^{-1}$ histamine concentrations. This can be explained by a weak enzyme immobilization on the WE when a lower GA concentration $(0.25 \%)$ is used, and a blocking effect of the electrode surface when a higher GA concentration $(0.75 \%)$ is used. Moreover, $0.50 \%$ GA provided the most precise results. Therefore, this GA concentration was chosen as an optimum concentration to develop the sensor.
Finally, the concentration of the mediator was also optimized. As can been seen in Fig. 2, a 5.0-mM hexacyanoferrate (III) solution provided a higher analytical signal for $75 \mathrm{mg} \mathrm{L}^{-1}$ of histamine than a $2.5-\mathrm{mM}$ solution. On the other hand, the precision for both histamine concentrations is better for a $5.0-\mathrm{mM}$ hexacyanoferrate (III) solution than for a $7.5-\mathrm{mM}$ solution. Therefore, $5.0 \mathrm{mM}$ of hexacyanoferrate (III) was chosen for the subsequent studies.

\section{Analytical features of the sensor}

To establish the analytical features of the developed sensor, chronoamperograms for different histamine concentrations were recorded (Additional file 1: Figure S2). A linear relationship between $\Delta i$ and the histamine concentration was found in the concentration range between 5.0 and $75.0 \mathrm{mg} \mathrm{L}^{-1}$ with a sensitivity of $38.9 \mathrm{nA} \mathrm{L} \mathrm{mg}^{-1} \mathrm{~cm}^{-2}$ and a correlation coefficient of 0.99991 (Fig. 3a). The limit of detection (LOD), calculated as $3 S_{b} / m$, and the limit of quantification (LOQ), calculated as $10 S_{b} / m$ (where $S_{b}$ is the standard deviation of the intercept and $m$ is the slope of the calibration plot) were 0.97 and $3.2 \mathrm{mg} \mathrm{L}^{-1}$, respectively. Additional file 1: Table S1 summarizes these and other figures of merit. This sensor exhibits high precision as demonstrated by the coefficient of variation, which is below $1.8 \%$. In order to assess the reproducibility of the results, five equally prepared sensors were used to measure $10-\mathrm{mg} \mathrm{L}^{-1}$ and $50-\mathrm{mg} \mathrm{L}^{-1}$ histamine solutions, obtaining RSD values of $3.4 \%$ and $3.1 \%$, respectively. When compared with previously reported electrochemical sensors for histamine detection, the developed sensor shows a comparable, or in some cases better, linear range, limit of detection, and/or precision (Table 1). This is more

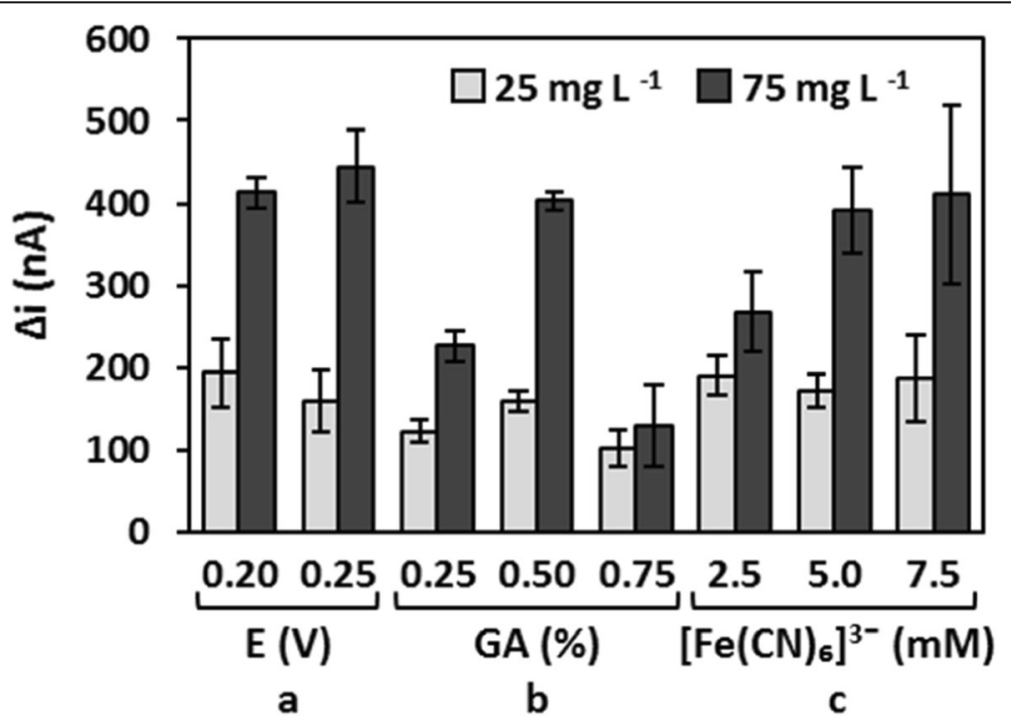

Fig. 2 Effect of the measuring potential and glutaraldehyde and hexacyanoferrate (III) concentration on the analytical signal $(\Delta i)$ for 25 and 75 $\mathrm{mg} \mathrm{L}^{-1}$ histamine. Experimental conditions: (a) DOX/GA/[Fe(CN) $\left.)_{6}\right]^{3-}, 0.50 \mathrm{mg} \mathrm{\mu L}^{-1} / 0.50 \% / 5.0 \mathrm{mM}$; (b) DOX/[Fe(CN) $]^{3-}, 0.50 \mathrm{mg} \mathrm{\mu L}^{-1} / 5.0 \mathrm{mM}$; and (c) DOX/GA, $0.50 \mathrm{mg} \mathrm{\mu L}^{-1} / 0.50 \%$. Average values \pm SD obtained with three different sensors are represented 


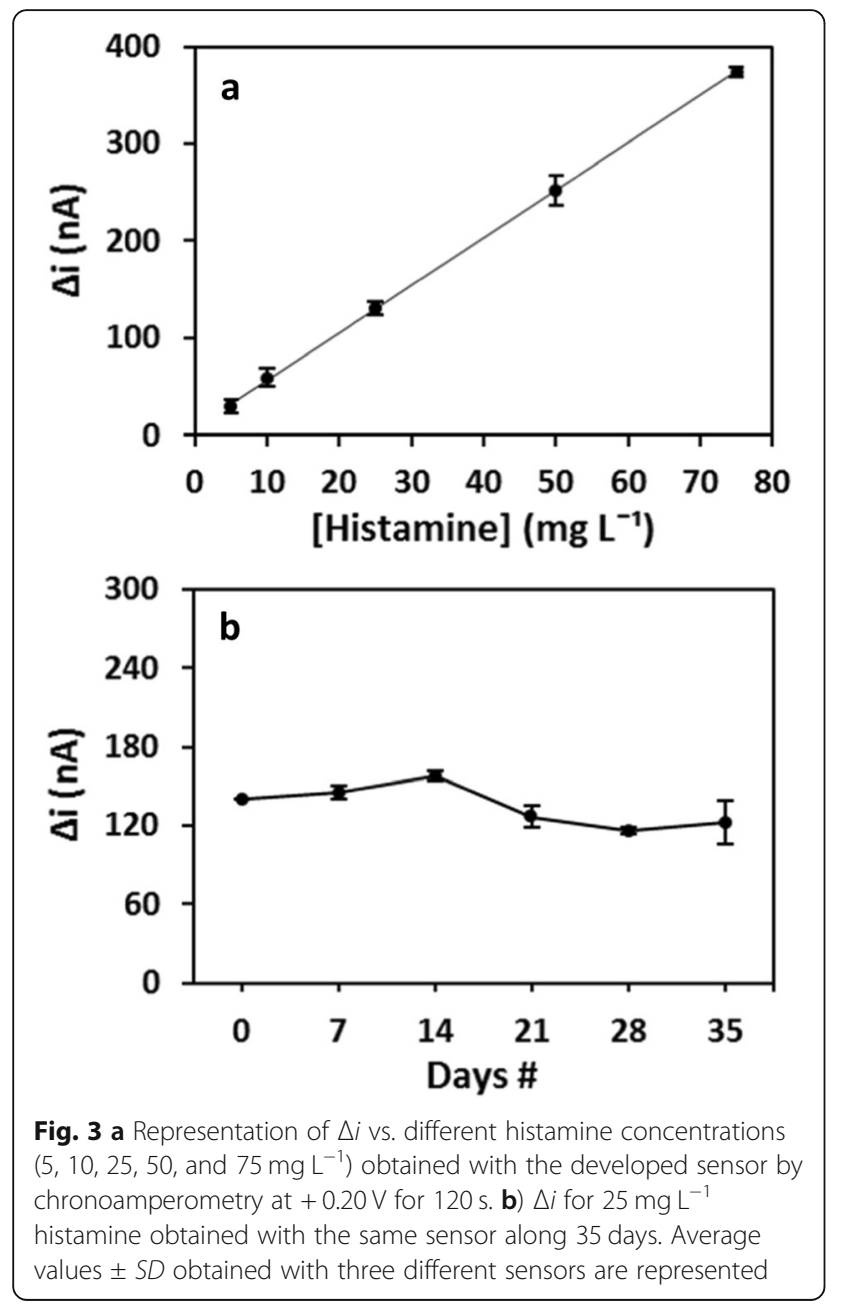

valuable considering its simplicity and the short construction time (just $30 \mathrm{~min}$ vs. $1.0-68 \mathrm{~h}$ necessary for other sensors).

\section{Stability}

To assess the stability of the sensor's response, three sensors were used to analyze $25-\mathrm{mg} \mathrm{L}^{-1}$ histamine solutions on the day of their construction and after 7, 14, 21, 28 , and 35 days. During this time, the sensors were stored at $4{ }^{\circ} \mathrm{C}$ and protected from light. As can be seen in Fig. 3b, after 35 days, the sensor maintained $87.7 \%$ of the initial analytical signal, showing storage stability comparable with other histamine sensors (see Table 1). Therefore, the developed sensor showed good stability that demonstrates the adequate immobilization of the enzyme while maintaining its bioactivity.

\section{Selectivity/interference studies}

The selectivity of the sensor towards histamine was evaluated by analyzing other biogenic amines that could be present in fish. Thus, the biosensor's response towards phenethylamine, spermine, tyramine, tryptamine, and putrescine was assessed by comparing the signal (current intensity) obtained for a $25-\mathrm{mg} \mathrm{L}^{-1}$ solution of histamine vs. the signal for $25-\mathrm{mg} \mathrm{L}^{-1}$ solutions of each biogenic amine. As shown in Fig. 4, the signal for all the other biogenic amines was similar to the signal obtained for the blank, confirming the selectivity of the proposed sensor. Moreover, when a mixture of biogenic amines (histamine + the other biogenic amines) was analyzed, the signal obtained was nearly the same as the one obtained for a $25-\mathrm{mg} \mathrm{L}^{-1}$ histamine solution $(417 \mathrm{nA} v s .451 \mathrm{nA}$, a

Table 1 Analytical characteristics of previously reported electrochemical devices for histamine

\begin{tabular}{|c|c|c|c|c|c|c|c|c|}
\hline Electrode & Construction & Detection & $\begin{array}{l}\text { Construction } \\
\text { time }(\mathrm{h})\end{array}$ & $\begin{array}{l}\text { Linear range } \\
\left(\mathrm{mg} \mathrm{L}^{-1}\right)\end{array}$ & $\begin{array}{l}\mathrm{LOD}(\mathrm{mg} \\
\left.\mathrm{L}^{-1}\right)\end{array}$ & RSD (\%) & $\begin{array}{l}\text { Storage } \\
\text { stability }\end{array}$ & Ref. \\
\hline$\overline{S P C E}$ & $\mathrm{DOX} / \mathrm{GA} /\left[\mathrm{Fe}(\mathrm{CN})_{6}\right]^{3-}$ & Amperometry & $\approx 0.5$ & $5-75$ & 0.97 & 3.4 & $\begin{array}{l}87.7 \% \\
35 \text { days }\end{array}$ & This work \\
\hline $\begin{array}{l}\text { SPCE (as } \\
\text { WE) }\end{array}$ & DOX/PhotoHEMA & Amperometry & n.r. & $5-60$ & 0.65 & 7.6 & & (Keow et al. 2012) \\
\hline SPCE & DOX/PhotoHEMA & & n.r. & $20-100$ & 2.46 & n.r. & n.r. & \\
\hline SPCE & $\begin{array}{l}{\left[\mathrm{Fe}(\mathrm{CN})_{6}\right]^{4-} / \mathrm{DOX} /} \\
\text { PhotoHEMA }\end{array}$ & & n.r. & $10-80$ & n.r. & n.r. & & \\
\hline SPCE & DOX/PhotoHEMA & Amperometry & n.r. & $5-60$ & 0.65 & 4.87 & n.r. & (Keow et al. 2007) \\
\hline SPCE & Nafion/ $\mathrm{Cu}_{3}\left(\mathrm{PO}_{4}\right)_{2}$ & Amperometry & $\approx 1$ & $5-100$ & 3 & 7.2 & n.r. & (Lee et al. 2018) \\
\hline SPCE & Rhenium(IV) oxide & Amperometry & $\approx 13$ & $0.5-10$ & 0.2 & 11 & n.r. & (Veseli et al. 2016) \\
\hline SPCE & $\begin{array}{l}\text { DOX/HRP/polysulfone/ } \\
\text { CNTs/ferrocene membrane }\end{array}$ & Amperometry & $\approx 1.5$ & $0.033-2.22$ & 0.018 & $5.6-6.5$ & $\begin{array}{l}\approx 90 \% \\
30 \text { days }\end{array}$ & (Pérez et al. 2013) \\
\hline ISE & MIP-NPs membrane & Potentiometry & $>48$ & $\begin{array}{l}0.11- \\
1111.5\end{array}$ & 0.12 & n.r. & $\begin{array}{l}\approx 100 \% \\
10 \text { days }\end{array}$ & $\begin{array}{l}\text { (Basozabal et al. } \\
\text { 2014) }\end{array}$ \\
\hline GCE & Thin film of mercury & Potentiometry & $\approx 0.5$ & $\begin{array}{l}1.5-10.5 \\
5-30 ; 20-90\end{array}$ & 1.31 & $\begin{array}{l}2.14- \\
2.99\end{array}$ & n.r. & $\begin{array}{l}\text { (Švarc-Gajić and } \\
\text { Stojanović 2011) }\end{array}$ \\
\hline GCE & $\begin{array}{l}\text { Ceria-polyaniline NPs/ } \\
\text { DOX/nafion }\end{array}$ & $C V$ & $>68$ & $50-116.7$ & 5.4 & $\begin{array}{l}0.05- \\
0.10\end{array}$ & $\begin{array}{l}86 \%, 18 \\
\text { days }\end{array}$ & (Gumpu et al. 2014) \\
\hline
\end{tabular}




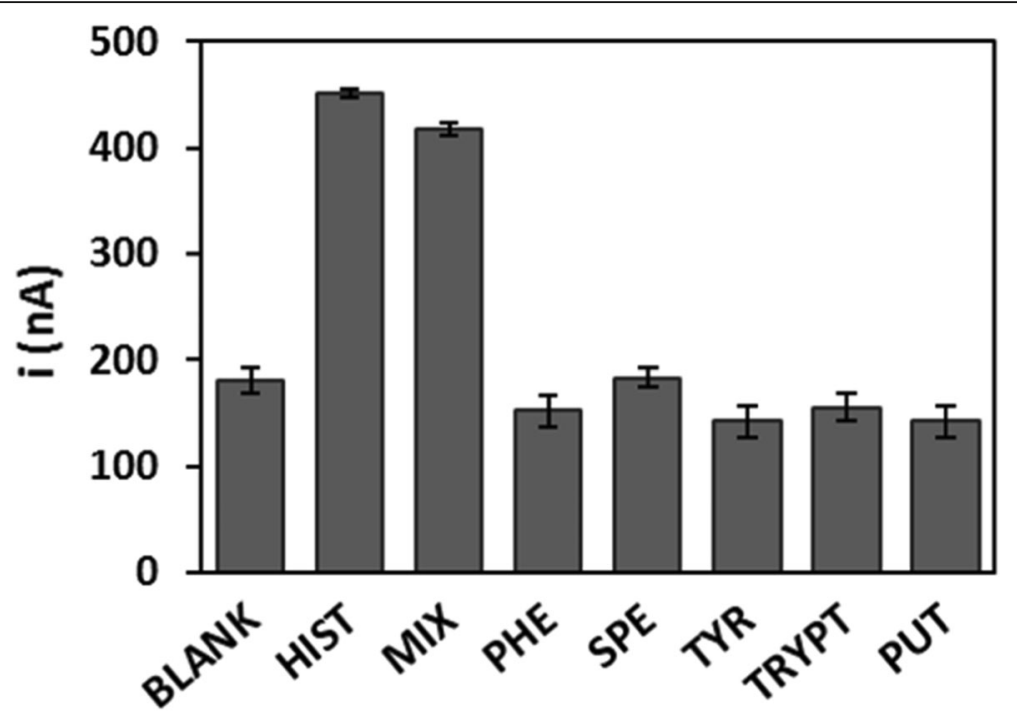

Fig. 4 Current intensities obtained for blank and for $25-\mathrm{mg} \mathrm{L}^{-1}$ solutions of histamine (HIST), phenethylamine (PHE), spermine (SPE), tyramine (TYR), tryptamine (TRYPT), and putrescine (PUT) and for a mixture containing $25 \mathrm{mg} \mathrm{L}^{-1}$ of each of these biogenic amines (MIX). Average values \pm SD obtained with three different sensors are represented

reduction of $7.5 \%)$, which indicates that the other biogenic amines do not significantly interfere in the analysis of histamine.

This demonstrates that the use of the redox mediator provides much better results in terms of selectivity towards histamine than when the analysis is performed through the reduction of the enzymatic products, as in our previous work (Torre et al. 2019), which showed signals for phenethylamine and spermine that were about $50 \%$ of the response for histamine.

\section{Recovery studies}

The feasibility of the sensor for the determination of histamine in real samples was assessed by recovery tests using spiked tuna and mackerel extracts (Table 2). The quantification of histamine was performed by recording chronoamperograms before and after spiking the extracts with a known amount of histamine. Recovery values of $96 \%$ and 97\% were obtained for tuna and mackerel, respectively. These results demonstrate the accuracy of the sensor and its ability to perform histamine analysis in fish samples. Moreover, they also demonstrate the benefits of this design (DOX + redox mediator) for histamine analysis in fish extracts since this sensor is not affected by matrix effects. So, and compared to the sensor without the use of a mediator (Torre et al. 2019), it is not necessary to construct calibration plots in fish extracts.

\section{Conclusions}

The importance of ensuring food safety has seen a huge growth due to consumer concerns about the food they eat. Therefore, the development of simple devices that allow rapid analysis to guarantee the safety of food is a field with increasing interest. In this work, a very simple sensor for histamine analysis was developed. The construction of this sensor only takes $30 \mathrm{~min}$, and it only requires $40 \mu \mathrm{L}$ of sample to perform the analysis. The sensor is able to determine histamine in a concentration range between 5 and 75 $\mathrm{mg} \mathrm{L}^{-1}$ with a good precision (coefficient of variation of $1.8 \%$ ). Moreover, the sensor can be constructed and stored since it maintains nearly $88 \%$ of its initial signal after 35 days when stored at $4{ }^{\circ} \mathrm{C}$. Its usefulness was demonstrated for histamine analysis in real fish extracts. The developed sensor fulfills several of the requirements of the current trends in analytical chemistry such as simplicity, low cost, small size, and requirement of low amounts of reagents and samples. Furthermore, the use of miniaturized electrodes (SPCEs) for the construction of the sensor and the

Table 2 Results of the recovery tests for the quantification of histamine in fish extracts. Average values \pm SD obtained with three different sensors are indicated

\begin{tabular}{lllll}
\hline & Histamine before spiking $\left(\mathrm{mg} \mathrm{L}^{-1}\right)$ & Histamine added $\left(\mathrm{mg} \mathrm{L}^{-1}\right)$ & Found value $\left(\mathrm{mg} \mathrm{L}^{-1}\right)$ & Recovery $(\%)$ \\
\hline Tuna & $14.0 \pm 0.2$ & 40 & $52.4 \pm 3.5$ & $96 \pm 8$ \\
Mackerel & $13.4 \pm 0.2$ & 25 & $37.7 \pm 1.4$ & $97 \pm 5$ \\
\hline
\end{tabular}


commercial availability of portable instrumentation (potentiostat) offer the possibility of decentralized analysis, which could be very useful for the control of histamine on-site along the whole fish production chain, from capture to consumption.

\section{Supplementary information}

Supplementary information accompanies this paper at https://doi.org/10. 1186/s40543-020-0203-3.

Additional file 1: Figure S1. Cyclic voltammogram of $\left[\mathrm{Fe}(\mathrm{CN})_{6}\right]^{4-}$. Figure S2. Chronoamperograms of different concentrations of histamine. Table S1. Figures of merit of the developed biosensor.

\section{Abbreviations \\ CE: Counter electrode; CNTs: Carbon nanotubes; CV: Cyclic voltammetry/ voltammogram; DOX: Diamine oxidase; GA: Glutaraldehyde; GCE: Glass carbon electrode; HIST: Histamine; HRP: Horseradish peroxidase; ISE: Ion- selective electrode; LOD: Limit of detection; LOQ: Limit of quantification; MIP: Molecularly imprinted polymer; n.r.: Not reported; NPs: Nanoparticles; PB: Phosphate buffer; PHE: Phenethylamine; PhotoHEMA: Photocured poly(2- hydroxyethyl) methacrylate; PUT: Putrescine; RE: (Pseudo)reference electrode; SPCE: Screen-printed electrode; SPE: Spermine; TRYPT: Tryptamine; TYR: Tyramine; WE: Working electrode}

\section{Acknowledgements}

Not applicable

\section{Authors' contributions}

This work was conceived by RT and ECR and is included in the project "FishBioSensing" of which CDM is the principal researcher. ECR designed and organized the studies and RT performed the experimental work. The analysis of the results was carried out by RT, ECR, and HPAN. RT and ECR wrote the draft of the manuscript and HPAN and CDM revised it critically. CDM and HPAN were responsible for the funding acquisition and the project administration. All authors read and approved the final manuscript.

\section{Funding}

This work was supported by UID/QUI/50006/2019 with funding from the Fundação para a Ciência e a Tecnologia (FCT)/the Ministério da Ciência, Tecnologia e Ensino Superior (MCTES) through national funds. The authors also thank FCT and the EU for funding through the projects:

FOODnanoHEALTH - Qualidade e Segurança Alimentar - uma abordagem (nano)tecnológica (Portugal2020, Norte-01-0145-FEDER-000011),

FishBioSensing - Portable electrochemical (bio)sensing devices for safety and quality assessment of fishery products (02/SAICT/2016, POCI-01-0145-FEDER023817), PTDC/ASP-PES/29547/2017 - CECs(Bio)Sensing - (Bio)sensors for assessment of contaminants of emerging concern in fishery commodities, (POCl-01-0145-FEDER-029547) and PTDC/QUI-QAN/30735/2017 TracAllerSens - Electrochemical sensors for the detection and quantification of trace amounts of allergens in food products (POCl-01-0145-FEDER030735), supported by national funds by FCT / MCTES and co-supported by Fundo Europeu de Desenvolvimento Regional (FEDER) through COMPETE 2020 - Programa Operacional Competitividade e Internacionalização. E. Costa-Rama thanks the Government of Principado de Asturias and Marie Curie-Cofund Actions for the post-doctoral grant "Clarín-Cofund" ACA17-20. R. Torre is grateful for her PhD grant from FCT (SFRH/BD/143753/2019), financed by POPH-QREN-Tipologia 4.1-Formação Avançada, and subsidized by FSE and MCTES.

\section{Availability of data and materials}

Research data have been provided in the manuscript and in the additional file.

\section{Competing interests}

The authors declare that they have no competing interest.
Received: 6 August 2019 Accepted: 6 January 2020

Published online: 05 February 2020

\section{References}

Akhoundian M, Rüter A, Shinde S. Ultratrace detection of histamine using a molecularly-imprinted polymer-based voltammetric sensor. Sensors. 2017;17: 1-10 https://doi.org/10.3390/s17030645.

Almeida C, Fernandes JO, Cunha SC. A novel dispersive liquid e liquid microextraction (DLLME) gas chromatography- mass spectrometry (GC e MS) method for the determination of eighteen biogenic amines in beer. Food Control. 2012;25:380-8 https://doi.org/10.1016/j.foodcont.2011.10.052.

Apetrei IM, Apetrei C. Amperometric biosensor based on diamine oxidase/ platinum nanoparticles/graphene/chitosan modified screen-printed carbon electrode for histamine detection. Sensors. 2016;16:1-15 https://doi.org/10. 3390/s16040422

Basozabal I, Guerreiro A, Gomez-Caballero A, Aranzazu Goicolea M, Barrio RJ. Direct potentiometric quantification of histamine using solid-phase imprinted nanoparticles as recognition elements. Biosens Bioelectron. 2014; 58:138-44 https://doi.org/10.1016/j.bios.2014.02.054

Biji KB, Ravishankar CN, Venkateswarlu R, Mohan CO, Gopal TKS. Biogenic amines in seafood: a review. J Food Sci Technol. 2016;53:2210-8 https://doi.org/10. 1007/s13197-016-2224-X.

Chaubey A, Malhotra BD. Mediated biosensors. Biosens Bioelectron. 2002;17:44156 https://doi.org/10.1016/S0956-5663(01)00313-X.

Daniel D, Bezerra V, Tadeu D, Vidal R, Lucio C. Determination of biogenic amines in beer and wine by capillary electrophoresis - tandem mass spectrometry. J Chromatogr A. 2015;1416:121-8 https://doi.org/10.1016/j.chroma.2015.08.065.

Dincer C, Bruch R, Costa-Rama E, Fernández-Abedul MT, Merkoçi A, Manz A, Urban GA, Güder F. Disposable sensors in diagnostics, food, and environmental monitoring. Adv Mater. 2019;1806739 https://doi.org/10.1002/adma.201806739.

Dong XX, Yang JY, Luo L, Zhang YF, Mao C, Sun YM, Lei HT, Shen YD, Beier RC, XU ZL. Portable amperometric immunosensor for histamine detection using Prussian blue-chitosan-gold nanoparticle nanocomposite films. Biosens Bioelectron. 2017;98:305-9 https://doi.org/10.1016/j.bios.2017.07.014.

Evangelista WP, Silva TM, Guidi LR, Tette PAS, Byrro RMD, Santiago-Silva P, Fernandes C, Gloria MBA. Quality assurance of histamine analysis in fresh and canned fish. Food Chem. 2016;211:100-6 https://doi.org/10.1016/j.foodchem. 2016.05.035.

Feng C, Teuber S, Gershwin ME. Histamine (scombroid) fish poisoning: a comprehensive review. Clin Rev Allergy Immunol. 2016;50:64-9 https://doi. org/10.1007/s12016-015-8467-x.

Geto A, Tessema M, Admassie S. Determination of histamine in fish muscle at multi-walled carbon nanotubes coated conducting polymer modified glassy carbon electrode. Synth Met. 2014;191:135-40 https://doi.org/10.1016/j. synthmet.2014.03.005.

Gorton L. Carbon paste electrodes modified with enzymes, tissues, and cells. Electroanalysis. 1995;7:23-45 https://doi.org/10.1002/elan.1140070104.

Gumpu MB, Nesakumar N, Sethuraman S, Krishnan UM, Rayappan JBB. Development of electrochemical biosensor with ceria-PANI core-shell nanointerface for the detection of histamine. Sensors Actuators B Chem. 2014;199: 330-8 https://doi.org/10.1016/j.snb.2014.04.009

Hungerford JM. Toxicon Scombroid poisoning: a review. Toxicon. 2010:56:231-43 https://doi.org/10.1016/j.toxicon.2010.02.006.

Keow CM, Abu Bakar F, Salleh AB, Heng LY, Wagiran R, Bean LS. An amperometric biosensor for the rapid assessment of histamine level in tiger prawn (Penaeus monodon) spoilage. Food Chem. 2007;105:1636-41 https:// doi.org/10.1016/j.foodchem.2007.04.027.

Keow CM, Bakar FA, Salleh AB, Heng LY, Wagiran R, Siddiquee S. Screen-printed histamine biosensors fabricated from the entrapment of diamine oxidase in a photocured poly(HEMA) film. Int J Electrochem Sci. 2012;7:4702-15.

Kung H-F, Huang C-Y, Lin C-M, Liaw L-H, Lee Y-C, Tsai Y-H. The histamine content of dried flying fish products in Taiwan and the isolation of halotolerant histamine-forming bacteria. J Food Drug Anal. 2015;23:335-42 https://doi. org/10.1016/j.jfda.2014.10.009

Lee M-Y, Wu C-C, Sari MI, Hsieh Y. A disposable non-enzymatic histamine sensor based on the nafion-coated copper phosphate electrodes for estimation of fish freshness. Electrochim Acta. 2018;283:772-9 https://doi.org/10.1016/j. electacta.2018.05.148.

Leonardo S, Campàs M. Electrochemical enzyme sensor arrays for the detection of the biogenic amines histamine, putrescine and cadaverine using magnetic 
beads as immobilisation supports. Microchim Acta. 2016;183:1881-90 https:// doi.org/10.1007/s00604-016-1821-8.

Nadeem M, Naveed T, Rehman F, Xu Z. Determination of histamine in fish without derivatization by indirect reverse phase-HPLC method. Microchem J. 2019;144:209-14 https://doi.org/10.1016/j.microc.2018.09.010.

Naila A, Flint S, Fletcher G, Bremer P, Meerdink G. Control of biogenic amines in food - existing and emerging approaches. J Food Sci. 2010;75:R139-50 https://doi.org/10.1111/j.1750-3841.2010.01774.x.

Nei D, Nakamura N, Ishihara K, Kimura M, Satomi M. A rapid screening of histamine concentration in fish fillet by direct analysis in real time mass spectrometry (DART-MS). Food Control. 2017;75:181-6 https://doi.org/10. 1016/j.foodcont.2016.12.001.

Off. J. Eur. Union. Comm. Regul. No 2073/2005 15 Novemb. 2005 Microbiological criteria for foodstuffs. https://eur-lex.europa.eu/legal-content/EN/ALL/?uri= CELEX\%3A32005R2073. Accessed 6 Aug 2019.

Ordóñez JL, Troncoso AM, García-Parrilla MDC, Callejón RM. Recent trends in the determination of biogenic amines in fermented beverages - a review. Anal Chim Acta. 2016;939:10-25 https://doi.org/10.1016/j.aca.2016.07.045.

Papageorgiou M, Lambropoulou D, Morrison C, Kłodzińska E, Namieśnik J, PłotkaWasylka J. Literature update of analytical methods for biogenic amines determination in food and beverages. TrAC - Trends Anal Chem. 2018;98: 128-42 https://doi.org/10.1016/j.trac.2017.11.001.

Pérez S, Bartrolí J, Fàbregas E. Amperometric biosensor for the determination of histamine in fish samples. Food Chem. 2013;141:4066-72 https://doi.org/10. 1016/j.foodchem.2013.06.125.

Quesada-González D, Merkoçi A. Mobile phone-based biosensing: an emerging "diagnostic and communication" technology. Biosens Bioelectron. 2017;92: 549-62 https://doi.org/10.1016/j.bios.2016.10.062.

R-Biopharm AG. https://food.r-biopharm.com/products/ridascreen-histaminenzymatic-2/. Accessed 6 Aug 2019.

Saghatforoush L, Hasanzadeh M, Shadjou N. Polystyrene-graphene oxide modified glassy carbon electrode as a new class of polymeric nanosensors for electrochemical determination of histamine. Chin Chem Lett. 2014;25: 655-8 https://doi.org/10.1016/j.cclet.2014.01.014.

Silva CCG, Da Ponte DJB, Dapkevicius MLNE. Storage temperature effect on histamine formation in big eye tuna and skipjack. J Food Sci. 1998;63:644-7.

Stojanović ZS, Mehmeti E, Kalcher K, Guzsvány V, Stanković DM. SWCNT-modified carbon paste electrode as an electrochemical sensor for histamine determination in alcoholic beverages. Food Anal Methods. 2016;9:2701-10 https://doi.org/10.1007/s12161-016-0452-3.

Švarc-Gajić J, Stojanović Z. Determination of histamine in cheese by chronopotentiometry on a thin film mercury electrode. Food Chem. 2011; 124:1172-6 https://doi.org/10.1016/j.foodchem.2010.07.030.

Torre R, Costa-Rama E, Lopes P, Nouws HPA, Delerue-Matos C. Amperometric enzyme sensor for the rapid determination of histamine. Anal Methods. 2019;11:1264-9 https://doi.org/10.1039/C8AY02610F.

Tsai Y-H, Chang S-C, Kung H-F, Wei C-I, Hwang D-F. Histamine production by enterobacter aerogenes in sailfish and milkfish at various storage temperatures. J Food Prot. 2005;68:1690-5.

Veseli A, Vasjari M, Arbneshi T, Hajrizi A, Švorc L, Samphao A, Kalcher K. Electrochemical determination of histamine in fish sauce using heterogeneous carbon electrodes modified with rhenium(IV) oxide. Sensors Actuators B Chem. 2016;228:774-81 https://doi.org/10.1016/j.snb.2016.01.085.

Visciano P, Schirone M, Tofalo R, Suzzi G. Histamine poisoning and control measures in fish and fishery products. Front Microbiol. 2014;5:1-3 https://doi. org/10.3389/fmicb.2014.00500.

Zarei M. Portable biosensing devices for point-of-care diagnostics: recent developments and applications. TrAC - Trends Anal Chem. 2017;91:26-41 https://doi.org/10.1016/j.trac.2017.04.001

Zeng K, Tachikawa H, Zhu Z, Davidson VL. Amperometric detection of histamine with a methylamine dehydrogenase polypyrrole-based sensor. Anal Chem. 2000;72:2211-5 https://doi.org/10.1021/ac9911138.

\section{Publisher's Note}

Springer Nature remains neutral with regard to jurisdictional claims in published maps and institutional affiliations.

\section{Submit your manuscript to a SpringerOpen ${ }^{\circ}$ journal and benefit from:}

- Convenient online submission

- Rigorous peer review

- Open access: articles freely available online

- High visibility within the field

- Retaining the copyright to your article

Submit your next manuscript at $\boldsymbol{\nabla}$ springeropen.com 